\title{
Activated Carbons from Molasses as $\mathrm{CO}_{2}$ Sorbents
}

\author{
J. MŁodzik*, J. Sreńscek-Nazzal, U. Narkiewicz, A.W. Morawski, R.J. Wróbel \\ AND B. MiCHALKIEWICZ \\ West Pomeranian University of Technology, Institute of Chemical and Environment Engineering, \\ K. Pułaskiego 10, 70-322 Szczecin, Poland
}

(Received July 3, 2015; in final form December 15, 2015)

Aim of this research is to obtain effective, molasses based activated carbon, which would adsorb big amounts of $\mathrm{CO}_{2}$. Molasses was mixed with $\mathrm{KOH}$. Weight ratio of dry materials was 1:1 (AC1, AC3) and 1:2 (only AC2). Homogeneous mixture was obtained. Material was left for $3 \mathrm{~h}$ at $25^{\circ} \mathrm{C}$. Drying lasted for $12 \mathrm{~h}$ at $200{ }^{\circ} \mathrm{C}$, and the material was grounded. The mixture was pyrolysed at $750{ }^{\circ} \mathrm{C}$, under constant flow $\left(18 \mathrm{dm}^{3} / \mathrm{min}\right)$ of nitrogen. The material was grounded again. Then, powder was washed with water, until filtrate was neutral, which took about $5 \mathrm{dm}^{3}$ of water. AC3 was washed with $1 \mathrm{dm}^{3}$ of water. After drying, materials were soaked in $\mathrm{HCl}\left(0.1 \mathrm{~mol} / \mathrm{dm}^{3}\right)$ for $19 \mathrm{~h}$, and washed with water, until filtrate was neutral. $\mathrm{CO}_{2}$ adsorption was performed under high pressure up to $40 \mathrm{~atm}$, at $40^{\circ} \mathrm{C}$. Specific surface area (according to the Brunauer-Emmett-Teller equation) was calculated for AC1, AC2 and AC3 and it is respectively 1985, 1967, and $2026 \mathrm{~m}^{2} / \mathrm{g}$, micropore volume - 0.714, 0.707, and $0.728 \mathrm{~cm}^{3} / \mathrm{g}$ and it was between $75 \%$ and $89 \%$ of total pore volume. The excess uptake at 40 atm pressure was as follows: AC1 - $14.02 \mathrm{mmol} / \mathrm{g}, \mathrm{AC} 2-12.75 \mathrm{mmol} / \mathrm{g}$, and AC3 - $15.79 \mathrm{mmol} / \mathrm{g}$.

DOI: 10.12693/APhysPolA.129.402

PACS/topics: 81.05.U-, 68.43.-h

\section{Introduction}

$\mathrm{CO}_{2}$ is considered as one of the biggest precursor of greenhouse effect $[1,2]$. Therefore there is a necessity to decrease the emission of this gas into the atmosphere. $\mathrm{CO}_{2}$ is one of the main component of post-combustion gases. Lots of different techniques was studied over the years, for example $\mathrm{CO}_{2}$ conversion to useful products [3]. One of the most popular is carbon capture and storage (CCS). Capturing of $\mathrm{CO}_{2}$ can be performed in precombustion or post-combustion stage of process. Nowadays it is the last one that is widely used. This process requires effective sorbent and reactor to perform the adsorption. One of the best gas-adsorbing materials is activated carbon $(\mathrm{AC})$. Vast surface area and porosity makes ACs potential highly impressive $[4,5]$. It is plausible to produce AC materials from almost every organic material, with relatively high content of carbon. Choosing the right material is actually crucial factor determining ACs adsorbing abilities and its surface properties $[6,7]$. In recent years huge attention is turned to residual wastes and agricultural products. It would be expected that the material will be efficient, cheap and within fairly easy reach. Plenty of raw materials were tested as such source e.g. residual wastes and agricultural products: straw, corn straw, corn cob and hulls, eucalyptus maculata, wheat birch wood, almond shells, nut shells, sunflower shells, peanut hulls, rice hulks, husks and straw, peach pits, cherry pits, apricot pits, olive pits and residues, pine cones and needles, rapeseed, miscanthus, sugarcane

*corresponding author; e-mail: jacek.mlodzik@zut.edu.pl bagasse [6-10]. Using such unusual material is a challenge, because preparation procedure, activating agent, physical and chemical properties of starting materials can influence the textural properties of ACs [11].

Great example of such underestimate material is molasses, which is residue from sugar producing process. Up until now, molasses has been considered as such carbon source just twice $[6,12]$, and it has been proven as very promising material to study. Results of this study was AC able to adsorb $11.76 \mathrm{mmol} / \mathrm{g}$ of $\mathrm{CH}_{4}$ at $40^{\circ} \mathrm{C}$ and $40 \mathrm{~atm}$ pressure, which at that time was considered as one of the most effective sorbents of that gas ever produced.

Aim of this research is to obtain molasses based activated carbon, which would be highly effective in $\mathrm{CO}_{2}$ adsorption. Results of $\mathrm{CH}_{4}$ adsorption are very promising. ACs produced from molasses, presented in this study, are according to our knowledge one of the most effective $\mathrm{CO}_{2}$ sorbents. We will also use solid state of $\mathrm{KOH}$, which can improve the textural properties of AC materials produced from molasses.

\section{Materials and methods}

Dense liquid, molasses, has been mixed with solid $\mathrm{KOH}$, which is an activating agent. Weight ratio, calculated for dry materials mass, was as follows: $\mathrm{AC} 1-1: 1$, $\mathrm{AC} 2-1: 1.2$ and AC3 - 1:1. Mixing has been continued until homogeneous mixture was obtained. Material was left for $3 \mathrm{~h}$ at $25^{\circ} \mathrm{C}$. Drying was provided for $12 \mathrm{~h}$ at $200^{\circ} \mathrm{C}$. Then, after grounding, the mixture was moved to quartz boat, and pyrolysis was performed. Temperature was $750^{\circ} \mathrm{C}$, at constant flow $\left(18 \mathrm{dm}^{3} / \mathrm{min}\right)$ of nitrogen. Material was grounded again. Then, powder was washed with water till filtrate $\mathrm{pH}$ was neutral which took about 
$5 \mathrm{dm}^{3}$ of water. AC3 was washed with $1 \mathrm{dm}^{3}$ only during the first washing. After drying, materials was soaked in $\mathrm{HCl}$ in concentration of $0.1 \mathrm{~mol} / \mathrm{dm}^{3}$ for $19 \mathrm{~h}$, and washed with water again to neutral $\mathrm{pH}$ of filtrate. In AC3 dish during soaking exothermal reaction was noticed.

Adsorption and desorption of liquid nitrogen at $-196^{\circ} \mathrm{C}$ was performed. Surface area $\left(S_{\mathrm{BET}}\right)$ was calculated on the basis of the Brunauer-Emmett-Teller (BET) equation. Micropore volume were calculated with density functional theory (DFT) method. $\mathrm{CO}_{2}$ adsorption was provided at pressure up to 40 atm, at temperature of $40^{\circ} \mathrm{C}$. Although these materials are designed as postcombustion sorbents of $\mathrm{CO}_{2}$, so the most interesting for us was their $\mathrm{CO}_{2}$ uptake at 1 atm pressure.

\section{Results and discussion}

The textural properties of obtained ACs are presented in Table I. Specific surface area of produced sorbents reaches $2000 \mathrm{~m}^{2} / \mathrm{g}$, total pore volume (TPV) reaches up to $0.95 \mathrm{~cm}^{3} / \mathrm{g}$. Furthermore, it is noticeable that all materials have high micropore volume (MP) to total pore volume ratios higher than $75 \%(\mathrm{AC} 1-75.7 \%$; $\mathrm{AC} 2-$ $89.1 \%$; AC3 - 76.8\%).

TABLE I

Activated carbons surface properties.

\begin{tabular}{c|c|c|c}
\hline \hline sample & $S_{\text {BET }}\left[\mathrm{m}^{2} / \mathrm{g}\right]$ & $\mathrm{TPV}\left[\mathrm{cm}^{3} / \mathrm{g}\right]$ & $\mathrm{MV}\left[\mathrm{cm}^{3} / \mathrm{g}\right]$ \\
\hline $\mathrm{AC} 1$ & 1985 & 0.9424 & 0.7138 \\
$\mathrm{AC} 2$ & 1967 & 0.794 & 0.7075 \\
$\mathrm{AC} 3$ & 2026 & 0.9481 & 0.7283
\end{tabular}

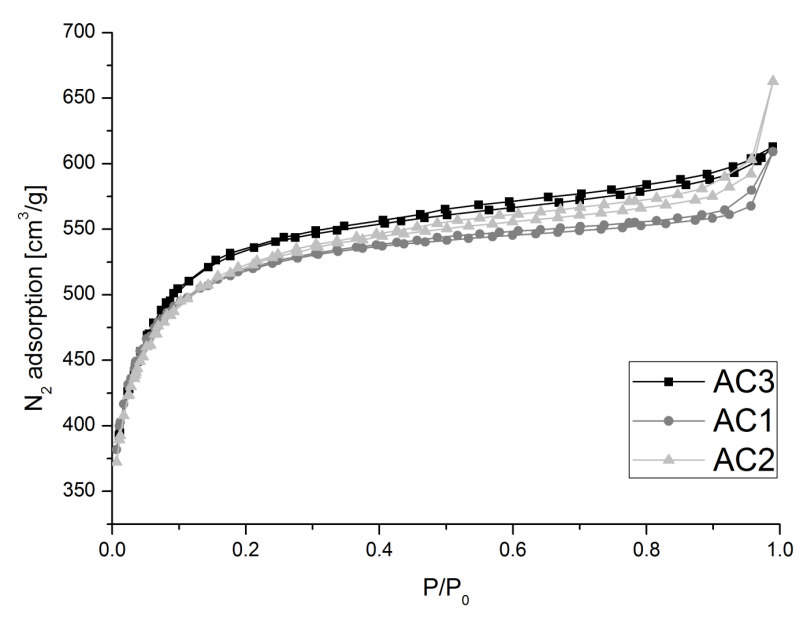

Fig. 1. Nitrogen adsorption and desorption isotherms.

Figure 1 shows isotherms of ACs, with hysteresis loops. Considering high uptake at low pressure, these are recognizable as type I isotherms, at high pressure though it is closer to type IV. Hysteresis loops, especially AC1 and AC2 are examples of mixed type H3 and H4 loops. Combined with isotherm these are exhibited, confirming

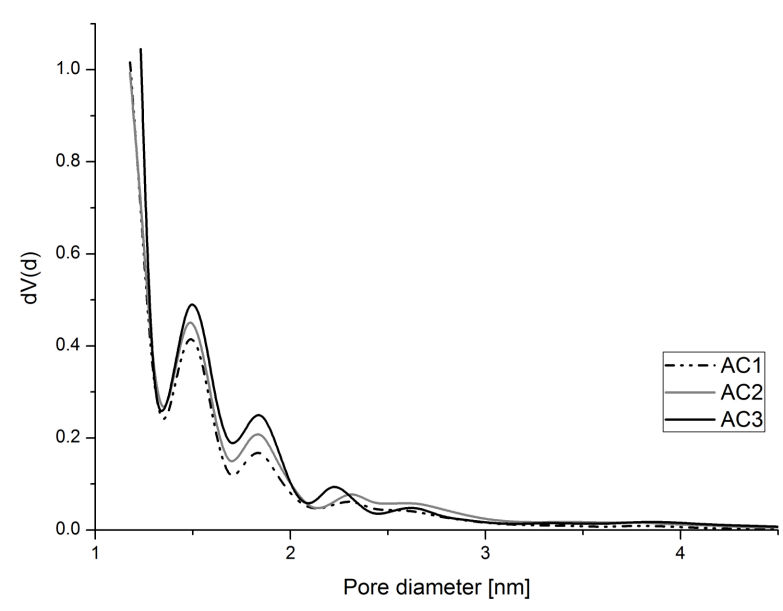

Fig. 2. Pore size distribution curve, calculated by DFT method.

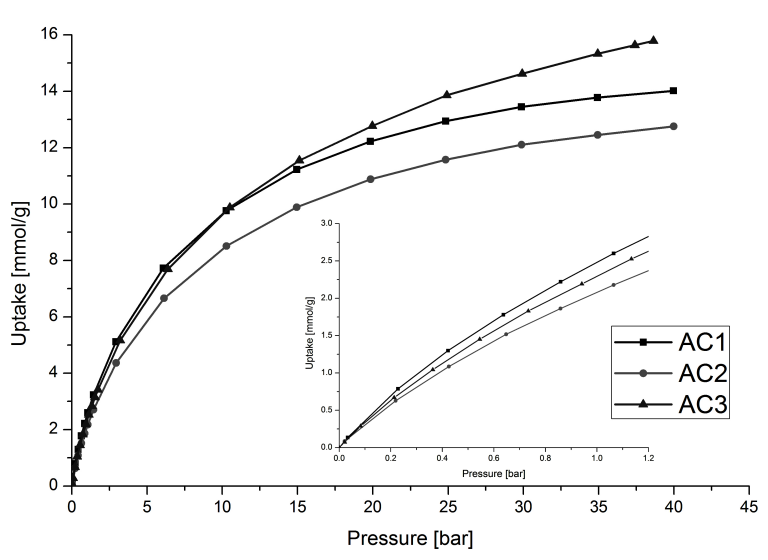

Fig. 3. Uptake of $\mathrm{CO}_{2}$ at pressure up to 40 bar.

that obtained structures are in fact microporous. It also suggests that there is no limited adsorption on these materials.

Figure 2 presents pore size distribution (PSD). Over $4.5 \mathrm{~nm}$ of diameter there was no pores found. On the basis of Fig. 2, it was found that obtained materials contain mostly micropores and small amount of mesopores of very low diameter. Pore diameter range is similar in each AC. AC3 developed the most microporous structure, which is probably a result of exothermal reaction noticed during the soaking with $\mathrm{HCl}$. This proves also information gathered in Table I. Considering AC1 and $\mathrm{AC} 2$, applying higher concentration of $\mathrm{KOH}$ increased the micropore volume.

Figure 3 reveals that at 1 atm, uptake of $\mathrm{CO}_{2}$ was as follows: $\mathrm{AC} 1-2.54 \mathrm{mmol} / \mathrm{g}, \mathrm{AC} 2-2.07 \mathrm{mmol} / \mathrm{g}$, $\mathrm{AC} 3-2.47 \mathrm{mmol} / \mathrm{g}$. Considering pressure up to $10 \mathrm{~atm}$, sorbents effectiveness was settled in certain order: AC1 > $\mathrm{AC} 3>\mathrm{AC} 2$. At about 11 atm pressure $\mathrm{AC} 1$ and $\mathrm{AC} 3$ adsorb the same amount of $\mathrm{CO}_{2}$ (about $9.97 \mathrm{mmol} / \mathrm{g}$ ). Over $11 \mathrm{~atm}$ of pressure effectiveness of sorbents was as 


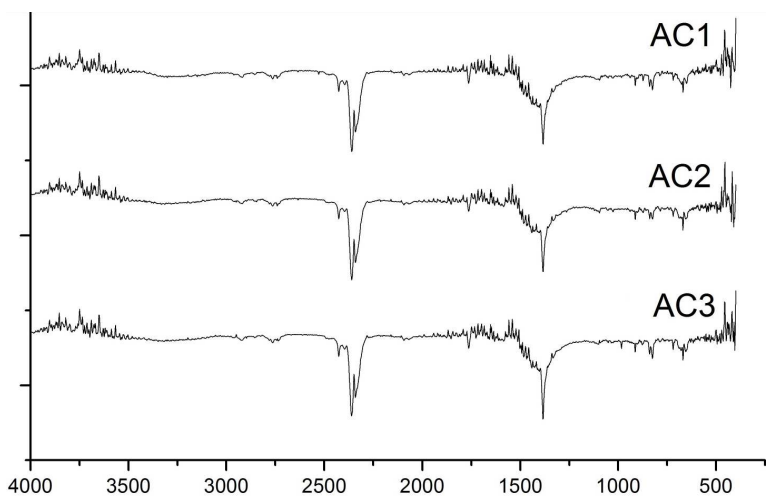

Fig. 4. FTIR results $\left(2380 \mathrm{~cm}^{-1} \mathrm{KBr}\right)$.

follows: $\mathrm{AC} 3>\mathrm{AC} 1>\mathrm{AC} 2 . \mathrm{AC} 1$ and $\mathrm{AC} 3$ are affected by the pressure of $\mathrm{CO}_{2}$ in very predictable matter. Such phenomenon can be explained by different surface structure of researched materials. Considering $\mathrm{AC} 1$ and $\mathrm{AC} 2$ we found that higher $\mathrm{KOH} / \mathrm{C}$ ratio decreases amount of adsorbed $\mathrm{CO}_{2}$ [7].

Figure 4 shows results of IR spectrum. At about $1380 \mathrm{~cm}^{-1}$ there is a band, which comes from bonds between aryl group and hydroxide group. At 2600$2950 \mathrm{~cm}^{-1}$ there are weak, but noticeable bands, which come from unsaturated bonds between carbon atoms. These are also noticeable at about $750-900 \mathrm{~cm}^{-1}$.

\section{Conclusions}

Chemical activation of molasses with solid $\mathrm{KOH}$ allows one to obtain high surface area activated carbons with a predominantly microporous structure. The $\mathrm{CO}_{2}$ uptakes reached $2.5 \mathrm{mmol} / \mathrm{g}$ at $40^{\circ} \mathrm{C}(\mathrm{AC} 1$ and $\mathrm{AC} 3)$. Such high $\mathrm{CO}_{2}$ adsorption was ascribable to the presence of high micropores content $(89 \%)$.

\section{Acknowledgments}

Project funded by the Norwegian funds, under the Polish-Norwegian Cooperation Research carried out by the National Centre for Research and Development, 2009-2014, No. Pol-Nor/237761/98/2014.

\section{References}

[1] A. Kondinya, S. Palash, M.K. Pandit, Int. J. Agr. Environm. Biotechnol. 7, 145 (2014).

[2] K. Wenelska, B. Michalkiewicz, J. Gong, T. Tang, R. Kaleńczuk, X. Chen, E. Mijowska, Int. J. Hydrogen En. 38, 16179 (2013).

[3] B. Michalkiewicz, J. Majewska, G. Kądziołka, K. Bubacz, S. Mozia, A.W. Morawski, J. $\mathrm{CO}_{2}$ Util. 5, 47 (2014).

[4] O. Ioannidou, A. Zabaniotou, Renew. Sust. En. Rev. 11, 1966 (2007).

[5] J. Sreńscek-Nazzal, U. Narkiewicz, A.W. Morawski, R.J. Wróbel, B. Michalkiewicz, J. Chem. Eng. Data 60, 3148 (2015).

[6] J. Sreńscek-Nazzal, W. Kamińska, B. Michalkiewicz, Z.C. Koren, Ind. Crops Prod. 47, 153 (2013).

[7] J. Sreńscek-Nazzal, B. Michalkiewicz, Pol. J. Chem. Technol. 4, 63 (2011).

[8] K.Y. Foo, B.H. Hameed, Micropor. Mesopor. Mater. 148, 191 (2012).

[9] K.Y. Foo, B.H. Hameed, Bioresour. Technol. 102 9814 (2011).

[10] S. Deng, H. Wei, T. Chen, B. Wang, J. Huang, G. Yu, Chem. Eng. J. 253, 46 (2014).

[11] H. Deng, G. Li, H. Yang, J. Tang, J. Tang, Chem. Eng. J. 163, 373 (2010).

[12] K. Legrouri, E. Khouya, M. Ezzine, H. Hannache, R. Denoyel, R. Pallier, R. Naslain, J. Hazard. Mater. B 118, 259 (2005). 